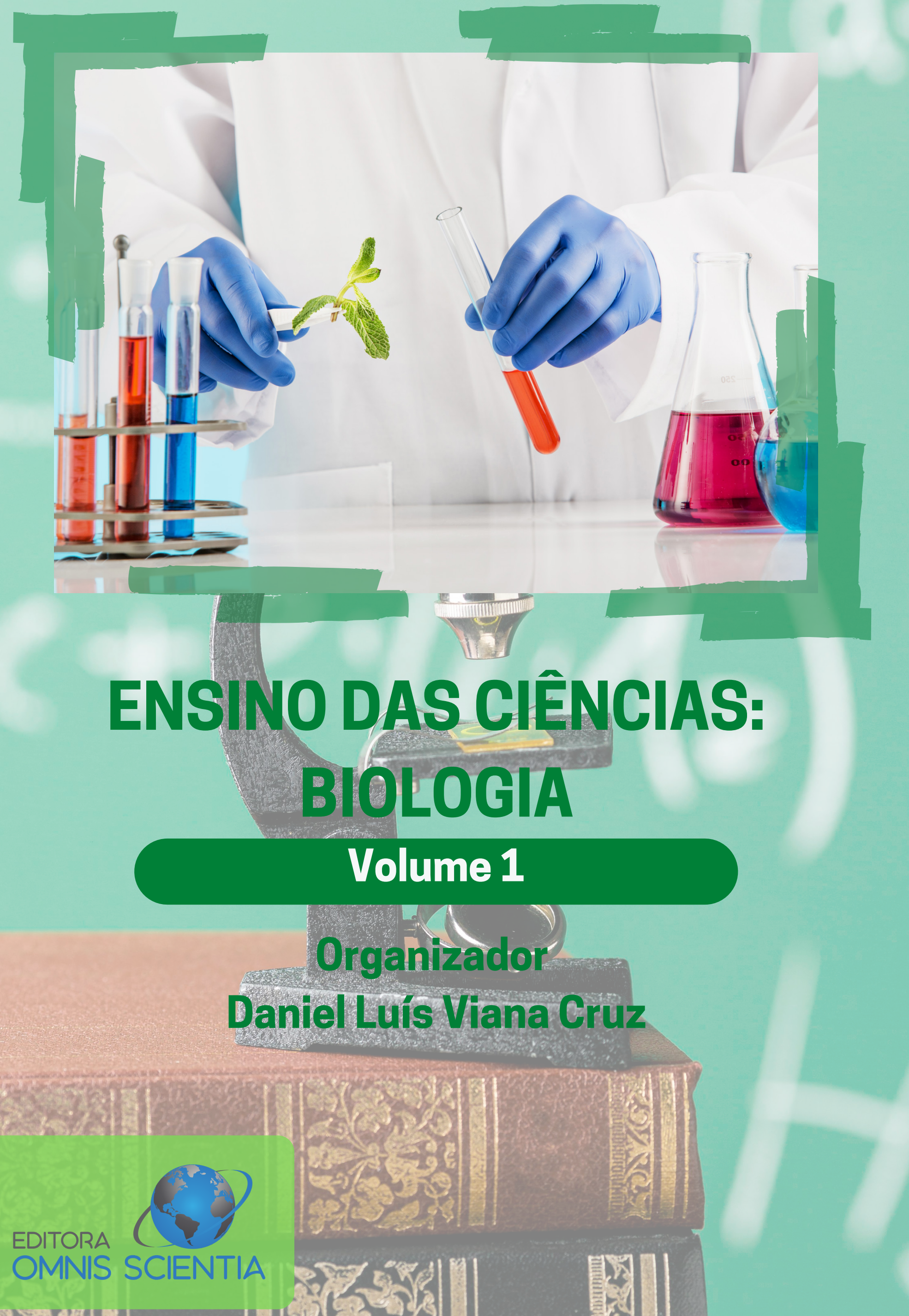




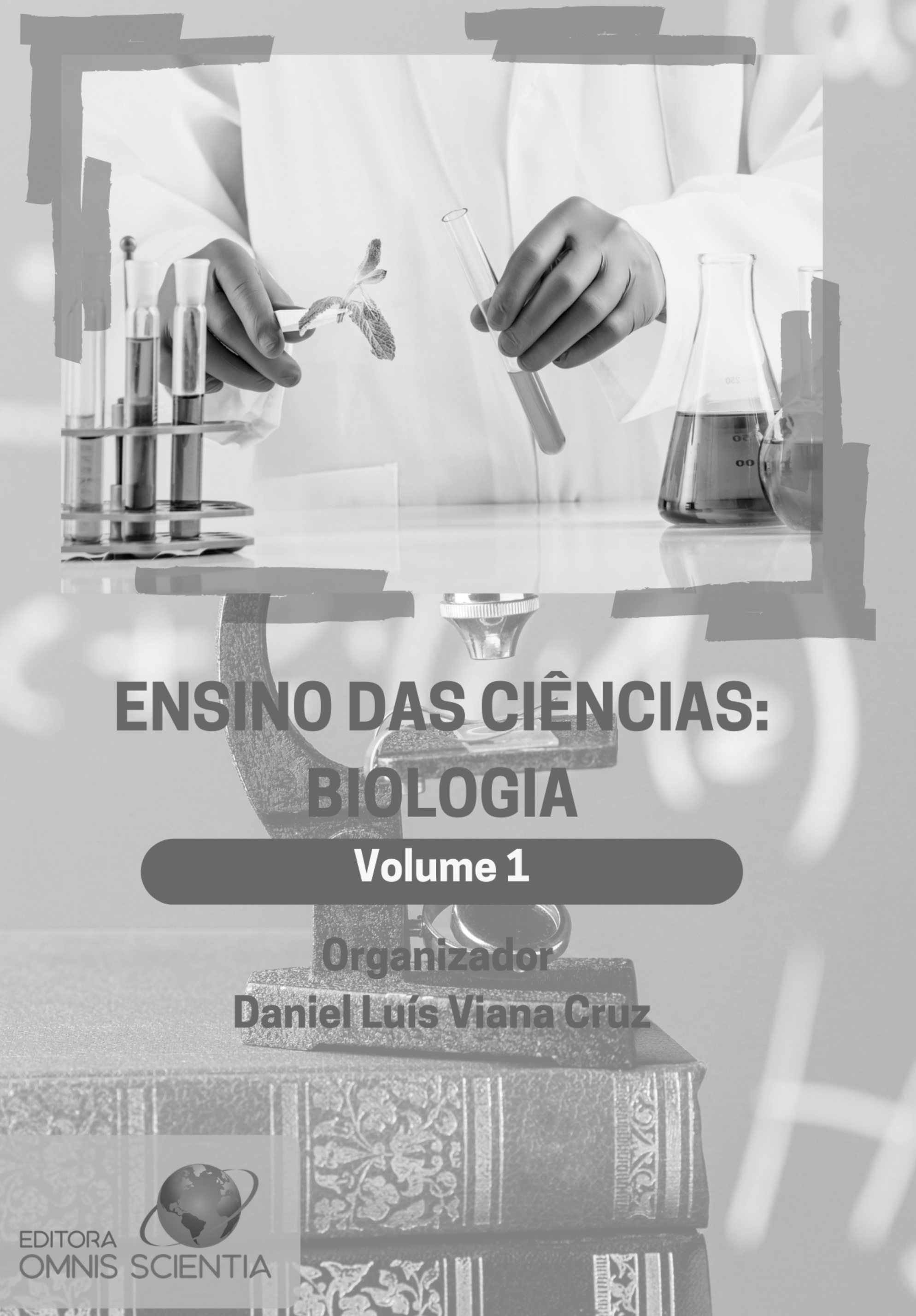


Editora Omnis Scientia

\section{ENSINO DAS CIÊNCIAS: BIOLOGIA}

Volume 1

$1^{\mathrm{a}}$ Edição

TRIUNFO - PE 


\section{Editor-Chefe}

Me. Daniel Luís Viana Cruz

Organizador (a)

Me. Daniel Luís Viana Cruz

\section{Conselho Editorial}

Dra. Pauliana Valéria Machado Galvão

Dr. Wendel José Teles Pontes

Dr. Walter Santos Evangelista Júnior

Dr. Cássio Brancaleone

Dr. Plínio Pereira Gomes Júnior

Editores de Área - Ciências Humanas

Dr. Cássio Brancaleone

Dr. José Edvânio da Silva

Assistentes Editoriais

Thialla Larangeira Amorim

Andrea Telino Gomes

Imagem de Capa

Freepik

\section{Edição de Arte}

Leandro José Dionísio

Revisão

Os autores

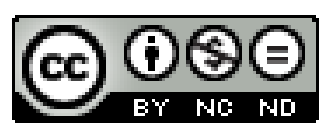

Este trabalho está licenciado com uma Licença Creative Commons - AtribuiçãoNãoComercial-SemDerivações 4.0 Internacional.

O conteúdo abordado nos artigos, seus dados em sua forma, correção e confiabilidade são de responsabilidade exclusiva dos autores. 


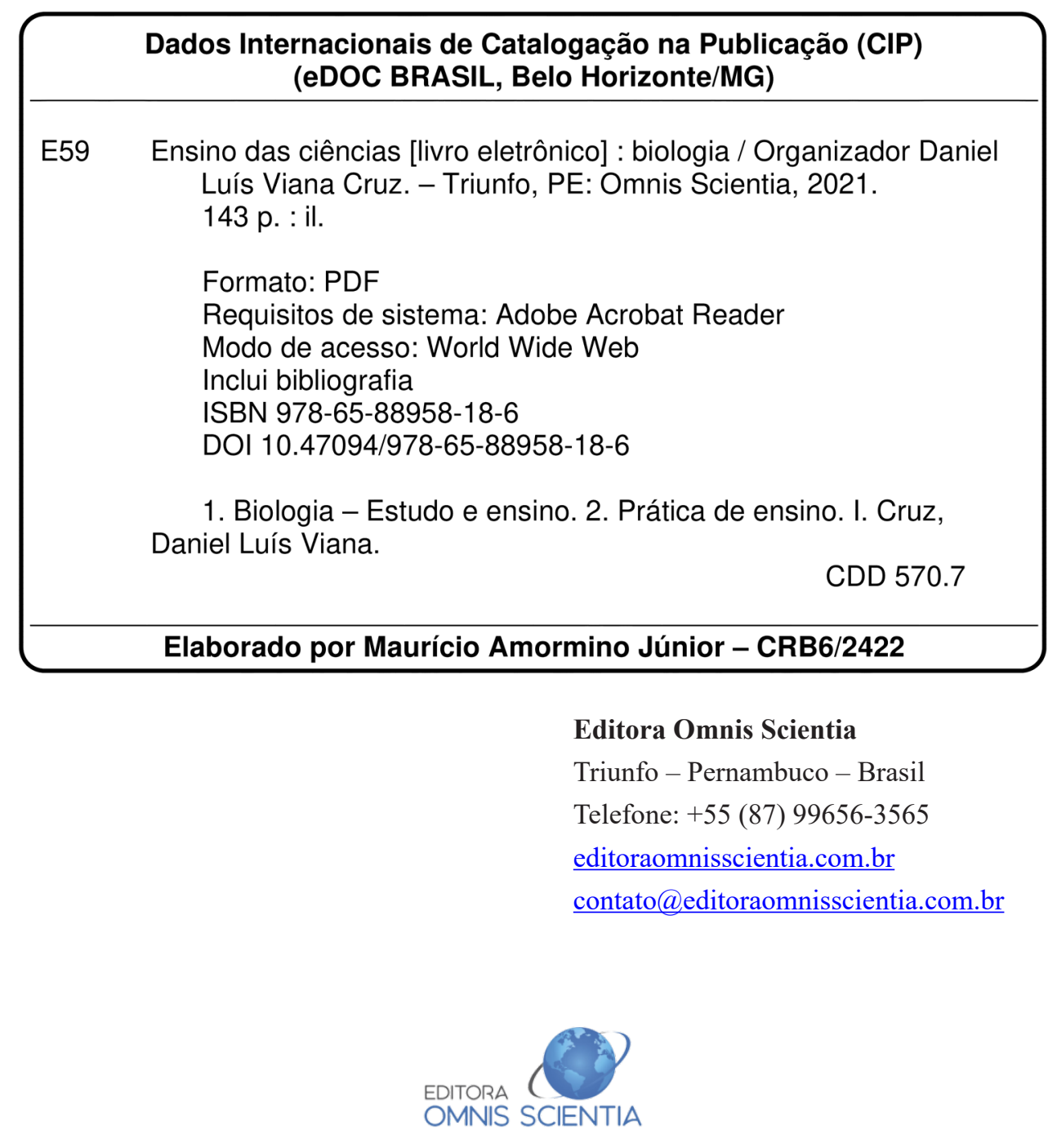




\section{PREFÁCIO}

O ensino é mais do que uma vocação, no país que vivemos trata-se de um sacerdócio. Ensinar, com poucos recursos e sem o merecido reconhecimento por parte da sociedade é persistir numa luta sem fim. Principalmente nesse período obscurecido pela desinformação e pelo negacionismo. Mas quando falamos de ensinar ciências, isso se torna ainda mais complexo, pois poucas escolas, sejam elas públicas ou privadas, possuem infraestrutura para aulas práticas. Que são tão importantes na fixação da informação. E assim os professores das ciências (Matemática, Física, Química e Biologia) seguem fazendo "mágica" nas salas de aula para que os alunos aprendam o mínimo necessário para a vida. Quando se trata de ensina Biologia, há muito que fazer com poucos recursos e o mínimo de boa vontade. E nessa obra o leitor poderá se inspirar em metodologias e ideias muito interessantes publicadas pelos autores.

Em nossos livros selecionamos um dos capítulos para premiação como forma de incentivo para os autores, e entre os excelentes trabalhos selecionados para compor este livro, o premiado foi o capítulo 3, intitulado "UM OLHAR PARA O ENFRENTAMENTO DAS VISÕES INGÊNUAS SOBRE A CIÊNCIA NO ENSINO DE BIOLOGIA”. 


\section{SUMÁRIO}

CAPÍTULO 1

AULAS REMOTAS DE CIÊNCIAS E BIOLOGIA DURANTE A PANDEMIA DO COVID-19 NA PERSPECTIVA DOS DISCENTES

Priscila Chaves de Souza

Hélio da Guia Alves Junior

DOI: $10.47094 / 978-65-88958-18-6 / 11-18$

CAPÍTULO 2 19

PRODUÇÃO E UTILIZAÇÃO DE MATERIAIS DIDÁTICOS NO ENSINO - APRENDIZAGEM DE DOENÇAS PARASITÁRIAS COMO: AMEBÍASE.

Sarah Lorena Silva Santos

Talessa Viegas Araujo

Samara Alves Correa

Lara Vitória Ribeiro Ferreia

Suelen Rocha Botão Ferreira

Lise Maria Mendes Holanda de Melo Ferreira

DOI: 10.47094/978-65-88958-18-6/19-27

CAPÍTULO 3 .28

UM OLHAR PARA O ENFRENTAMENTO DAS VISÕES INGÊNUAS SOBRE A CIÊNCIA NO ENSINO DE BIOLOGIA

Elda Cristina Carneiro da Silva;

Joanez Aparecida Aires

DOI: 10.47094/978-65-88958-18-6/28-41 
CAPÍTULO 4

ABORDAGEM DO TEMA SISTEMAS DE ENTREGA DE FÁRMACOS NO ENSINO FUNDAMENTAL

Edmilson Clarindo de Siqueira

José Adonias Alves de França

Silvana Caroline de Holanda

DOI: $10.47094 / 978-65-88958-18-6 / 42-52$

CAPÍTULO 5

A NANOTECNOLOGIA APLICADA AO ENSINO DE CIÊNCIAS

Edmilson Clarindo de Siqueira

José Adonias Alves de França

Silvana Caroline de Holanda

Fábio Rocha Formiga

DOI: $10.47094 / 978-65-88958-18-6 / 53-64$

CAPÍTULO 6 .65

OFICINAS DE CORDEL COM TEMAS DE BIOLOGIA

Edmilson Clarindo de Siqueira

José Adonias Alves de França

Silvana Caroline de Holanda

DOI: $10.47094 / 978-65-88958-18-6 / 65-75$

CAPÍTULO 7.

RELAÇÃO HOMEM E NATUREZA NAS MARGENS DO RIO PERICUMÃ NA CIDADE DE PINHEIRO-MA

Gabrielly Soares Dias Gonçalves 
Jenilce Monica Ferreira Fernandes

Werberth Braga Bastos

Hellen José Daiane Alves Reis

DOI: $10.47094 / 978-65-88958-18-6 / 76-86$

CAPÍTULO 8 .87

METODOLOGIAS ATIVAS NO ENSINO DE FISIOLOGIAHUMANA: O OLHAR DOS FUTUROS PROFESSORES

Maria Iracema Barbosa Moura

Francisco de Assis Pereira da Silva

Helayne Barbosa Moura

DOI: 10.47094/978-65-88958-18-6/87-96

CAPÍTULO 9 97

CORRIDA DE ESPERMATOZOIDES: SEXO E HERANÇA - UMA PROPOSTA INTERATIVA PARA O ENSINO DE HEREDITARIEDADE

Fernanda Pacheco-Fernandes

Benn Richard Alle

Iris Hass

Luciane Viater Turek

Maíra Alexandre Peres

Lupe Furtado-Alle

DOI: $10.47094 / 978-65-88958-18-6 / 97-112$

CAPÍTULO 10 113

DANÇA DOS CROMOSSOMOS: USANDO A LUDICIDADE PARA ENSINAR HEREDITARIEDADE 
Fernanda Pacheco-Fernandes

Benn Richard Alle

Iris Hass

Luciane Viater Tureck

Maíra Alexandre Peres

Lupe Furtado-Alle

DOI: $10.47094 / 978-65-88958-18-6 / 113-126$

CAPÍTULO 1

A DiscuSSÃO DA HOMOSSEXUALIDADE EM UM LIVRO PARADIDÁTICO DE SEXUALIDADE

Lucas Mendes Silva

Vitoria Raquel Pereira de Souza

Jackson Ronie Sá-Silva

DOI: $10.47094 / 978-65-88958-18-6 / 127-137$ 


\title{
AULAS REMOTAS DE CIÊNCIAS E BIOLOGIA DURANTE A PANDEMIA DO COVID-19 NA PERSPECTIVA DOS DISCENTES
}

\author{
Priscila Chaves de Souza \\ Unibr, São Vicente, São Paulo \\ http://lattes.cnpq.br/0298768655705062
}

\author{
Hélio da Guia Alves Junior \\ Unibr, São Vicente, São Paulo \\ http://lattes.cnpq.br/2214315704472172
}

\begin{abstract}
RESUMO: em meio à pandemia causada pela livre circulação do vírus SARS-CoV-2, a medida tomada pelo Ministério da Educação junto ao Ministério da Saúde foi o fechamento das escolas e suspensão das aulas presenciais. Por segurança e para minimizar prejuízos, o conteúdo didático começou a ser oferecido de forma remota. Por conta disso, surgiu a necessidade de questionar quais são as dificuldades que os alunos encontraram neste formato de aprendizagem. Objetivo: Este trabalho teve como objetivo identificar dificuldades do aprendizado de Ciências e Biologia no contexto do ensino remoto promovido pela pandemia do COVID-19. Metodologia: Os dados da pesquisa foram obtidos em escolas públicas da região da Baixada Santista, no litoral de São Paulo, por meio de questionário on-line, divulgado publicamente para ser acessado por jovens em idade escolar, contando com 30 participantes. Resultados: Observa-se que 95\% preferem aulas presenciais; $68 \%$ relataram dificuldade de se comunicar com o professor por meio das plataformas digitais; $53 \%$ afirmaram que possuem ambiente favorável para realizar as atividades remotas; $53 \%$ acessavam pelo celular e $47 \%$ pelo computador; $11 \%$ dos alunos precisaram pegar emprestado algum dispositivo eletrônico para acessar as aulas; 32\% precisaram buscar material impresso na escola; 43\% não estão plenamente satisfeitos com o material; 53\% afirmaram dedicar menos de uma hora semanal para os estudos de Ciências ou Biologia. Conclusões: As principais dificuldades com as aulas remotas foram falhas ou ausência da conexão de internet, ambiente desfavorável para a concentração nos estudos, dificuldade de entender os conceitos e a ausência de interação física durante as aulas.
\end{abstract}

PALAVRAS-CHAVE: Educação básica. Inclusão. Dificuldades de aprendizagem.

\author{
REMOTE SCIENCE AND BIOLOGY CLASSES DURING THE COVID-19 PANDEMIC \\ FROM THE PERSPECTIVE OF DISCENTS
}


ABSTRACT: through the pandemic caused by the free circulation of the SARS-CoV-2 virus, the measure taken by the Ministry of Education with the Ministry of Health was the closure of schools and the suspension of face-to-face classes. For security and to minimize losses, didactic content began to be offered remotely. Because of this, the need arose to question what are the difficulties that students encountered in this learning format. Objective: this study aimed to identify difficulties in learning Science and Biology in the context of remote education promoted by the pandemic of COVID-19. Methodology: The research data were obtained in public schools in the region of the city of Santos, on the coast of São Paulo, through an online questionnaire, publicly disclosed to be accessed by school-age youth, with 30 participants. Results: It is observed that $95 \%$ prefer face-toface classes; $68 \%$ reported difficulty communicating with the teacher through digital platforms; $53 \%$ stated that they have a favorable environment to carry out remote activities; $53 \%$ accessed by cell phone and $47 \%$ by computer; $11 \%$ of students had to borrow an electronic device to access classes; $32 \%$ had to look for printed material at school; $43 \%$ are not fully satisfied with the material; $53 \%$ said they devote less than an hour a week to science or biology studies. Conclusions: The main difficulties with remote classes were failures or lack of internet connection, unfavorable environment for concentration in studies, difficulty in understanding the concepts and the absence of physical interaction during classes.

KEY WORDS: Basic education. Inclusion. Learning difficulties.

\section{INTRODUÇÃO}

O presente estudo, oriundo de um trabalho de conclusão de curso de licenciatura em Ciências Biológicas, teve origem no decorrer da pandemia causada pela livre circulação do vírus SARS-CoV-2, em que as medidas tomadas pelos Ministérios da Educação da Saúde culminaram no fechamento das escolas e suspensão do aprendizado presencial. Neste cenário, para garantir a segurança e minimizar os possíveis prejuízos educacionais, o conteúdo didático tem sido fornecido remotamente, tendo como meios mais comuns os materiais impressos, os quais podem ser coletados nas escolas, materiais on-line, para acesso por meio de computadores ou telefones celulares, transmissão de televisão por canais de sinal aberto e rádio.

O levantamento de hipóteses sobre as dificuldades encontradas pelos estudantes mostrou algumas informações alarmantes, já que, segundo o Fundo das Nações Unidas para a Infância (UNICEF, 2020), a necessidade de confinamento deixa as crianças e adolescentes mais vulneráveis aos abusos e violências.

Além disso, a intranquilidade emocional é uma das principais interferências na falta de concentração, já que o estudante em qualquer idade necessita de um ambiente adequado para desenvolver a aprendizagem, "Um aspecto que, regularmente, interfere no aprendizado relaciona-se a distração, desatenção e concentração” (LIMA; QUEIROZ; SANT’ANNA, 2018, p. 12). 
Dentro dessa perspectiva, é preciso levar em consideração que o caminho da aprendizagem é um processo construído pelo próprio indivíduo em parceria com escola, professores e sociedade, já que "A inteligência humana somente se desenvolve no indivíduo em função de interações sociais que são, em geral, demasiadamente negligenciadas" (PIAGET, 1967, apud LA TAILLE, 1992, p.11).

Tendo isso em mente, muito se tem discutido a respeito da evolução intelectual relacionada à interação social no ambiente escolar, e o aprofundamento nessa questão demonstra que a relação escola-sociedade é essencial para o desenvolvimento intelectual e social dos jovens.

Por esse motivo, a percepção do processo de aprendizagem não pode ser vista apenas sob o prisma dos conteúdos, já que a interação humana e processo de socialização ocorrem de forma privilegiada no âmbito escolar, favorecendo o desenvolvimento das potencialidades dos alunos.

Vimos que tal evolução passa por diferenças de qualidade das trocas intelectuais, podendo o indivíduo mais evoluído usufruir plenamente tanto de sua autonomia quanto dos aportes dos outros. Assim, longe de significar isolamento e impermeabilidade às ideias presentes na cultura, autonomia significa ser capaz de se situar consciente e competentemente na rede dos diversos pontos de vista e conflitos presentes numa sociedade. Vimos, por fim, que as diversas etapas que definem qualidades diferenciadas do "ser social" acompanham as etapas do desenvolvimento cognitivo. Cabe perguntar agora que influência têm as interações sociais sobre esse desenvolvimento (TAILLE; OLIVEIRA; DANTAS, 1992. p.11).

Por isso, se faz tão importante a abordagem humanista, descrita por Carl Rogers como precursora da aprendizagem significativa, mostrando a interação aluno-professor como protagonista de confiança e estímulo, pois “[...] ela instaurará um diálogo direto com o aluno sobre a base de uma relação de pessoa a pessoa, que é ela mesma, sem subterfúgio nem censura" (ROGERS, 1983, p. 106), tendo no âmbito da aula presencial um grande fator de favorecimento da interação entre estudantes e professores, mas as aulas remotas nem sempre podem contemplar o discente com este benefício.

Embora o MEC tenha buscado diversas formas de disponibilizar o material didático e os professores estarem on-line na internet durante as aulas ou por meio de vídeos pré-gravados e transmissão pela televisão, algumas crianças não tiveram oportunidade de esclarecimento de dúvidas imediatas, necessitando, assim, contar com a ajuda de familiares ou da coordenação da escola, já que aqueles que estudam por meio do material impresso não possuem acesso à internet. Com isso, a indisponibilidade dos meios de acesso tem sido o problema que costuma ser o principal obstáculo para a viabilização do ensino remoto.

Uma pesquisa divulgada pelo Instituto Brasileiro de Geografia e Estatística (IBGE) em abril de 2020 mostrou que um em cada quatro brasileiros não tem acesso à internet, número que representa 46 milhões de pessoas sem acesso à rede. Além disso, para que o aluno tenha a possibilidade de interação virtual com os professores e colegas, é necessário que ele disponha de um aparelho para realizar a conexão, como tablet, celular ou computador, sendo de uso particular, compartilhado ou emprestado. Desta forma, o contexto social e econômico em que o estudante está inserido delimita o 
leque de oportunidades para aprendizagem que esse indivíduo encontrará.

Não são todos os alunos que durante a pandemia podem contar com livros, sites de conteúdo educacional ou experiências práticas relativas ao ensino de Ciências e Biologia. Na escola, o professor pode contribuir com a aprendizagem, ofertando métodos de experimentação prática, seja nos jardins ou no laboratório. A artigo do professor José Moran intitulado Metodologias ativas para realizar transformações progressivas e profundas no currículo, defende que o ativismo discente no aprendizado não é apenas uma forma de melhorar o nível de conhecimento do aluno, mas também uma oportunidade de desenvolvimento social, já que "As metodologias ativas são caminhos para avançar mais no conhecimento profundo, nas competências socioemocionais e em novas práticas" (2013, p. 1).

Contudo, o estudo das ciências tem sido amplamente discutido por autores que destacam o valor social do conhecimento científico. Crianças, jovens e adultos constroem, em suas práticas sociais cotidianas, um conhecimento do mundo que os cerca. Esse conhecimento cotidiano, ou do senso comum, permite-nos interagir de uma forma bastante eficiente com nossa realidade natural e social. Poderíamos argumentar que não é necessário ter acesso a um conhecimento científico da realidade para interagir com ela. No entanto, o que tratamos é da qualidade de interpretação (WEISSMANN, 1998, p. 17).

A afirmação de Vygotsky (1989, p. 75), “O saber que não vem da experiência não é realmente saber", nos mostra a importância da participação ativa do estudante durante o processo de aprendizado, buscando informações e realizando as atividades. Porém, durante uma pandemia, e sob a recomendação de permanecer dentro de casa até que aconteça a imunização mundial, é necessário criar tarefas adequadas à realidade de cada aluno para que haja a experimentação e não apenas o conteúdo teórico.

A construção do saber é o foco deste trabalho, sem conhecer a perspectiva dos alunos não há como realizar um ensino eficiente, a boa didática beneficia a evolução educacional individual, já que ela, conforme Rogers (1969, p. 114), "Se efetiva mais rapidamente quando o indivíduo busca uma finalidade precisa e quando ele julga os materiais didáticos que lhe são apresentados como capazes de lhe permitir atingi-la mais depressa."

Desta forma, o objetivo geral deste trabalho foi identificar dificuldades no aprendizado de Ciências e Biologia no contexto do ensino remoto promovido pela pandemia do COVID-19, elencando como objetivos específicos (i) estudar o ensino remoto e os conceitos principais da educação a distância; (ii) coletar perspectivas das dificuldades enfrentadas pelos alunos durante o ensino remoto; (iii) refletir criticamente sobre as dificuldades dos alunos.

\section{METODOLOGIA}

Após revisão bibliográfica, foi elaborado um questionário construído em 13 questões, sendo 
8 de múltipla escolha e 5 dissertativas opcionais para esclarecimento das respostas anteriores. $\mathrm{O}$ questionário foi fornecido em formato digital e hospedado em um site. Após a anuência do responsável legal do aluno e aprovação da direção escolar, os professores divulgaram o link de acesso para que os alunos pudessem participar. Por meio do endereço eletrônico, os estudantes puderam expressar sua experiência e discutir suas opiniões.

Por se tratar de um estudo com exploratório, optou-se por utilizar métodos quanti-qualitativos para obter melhor qualidade dos resultados, conforme a Goldenberg (2004 pg. 62), “A integração da pesquisa quantitativa e qualitativa permite que o pesquisador faça um cruzamento de suas conclusões de modo a ter maior confiança que seus dados não são produto de um procedimento específico ou de alguma situação particular."

\section{RESULTADOS E DISCUSSÕES}

Com a participação de 30 alunos, os resultados parciais demonstram que 93\% dos participantes preferem aulas presenciais de Ciências e Biologia, essa preferência foi justificada pelos fatores de ambiente mais adequado para concentração nos estudos, possibilidade de realizar experimentos em sala de aula/laboratório e a interação mais intensa com o professor e colegas de sala, facilitando o esclarecimento de dúvidas, como nestes exemplos 1 e 2 abaixo:

1. "Porque eu conseguia entender a explicação e facilitava o aprendizado." (Aluno A, $1^{\circ}$ ano E.M.)

2. "Consigo aprender melhor com gestos e brincadeiras, slides não funcionam muito bem comigo.” (Aluno B, $3^{\circ}$ ano E.M.)

As declarações dos alunos sobre a necessidade de realização de experimentos junto ao docente demonstram a importância da investigação na construção da aprendizagem, em consonância como o que preconiza Moran (2017, p.23) dedicadas à construção de uma relação mais ativa do aluno, em que ele deve ser protagonista das situações pedagógicas, levando em consideração que "A aprendizagem ativa dá ênfase ao papel protagonista do aluno, ao seu envolvimento direto, participativo e reflexivo em todas as etapas do processo, experimentando, desenhando, criando, com orientação do professor".

Além disso, 73\% relataram dificuldade de se comunicar com o professor por meio das plataformas digitais, alegando instabilidade da internet, como no exemplo a seguir:

3. "Problemas de internet/plataforma." (Aluno C, $4^{\circ}$ ano E.F.)

E, de fato, em agosto de 2020, o site da Agência Nacional de Telecomunicações (ANATEL) publicou o aumento de 6,6\% devido à inconsistência da banda larga fixa, segundo os consumidores. Houve o registro de 394 mil reclamações totalizando um crescimento de $40 \%$ em relação ao semestre anterior.

$52 \%$ afirmaram que possuem ambiente favorável para realizar as atividades remotas, por não 
sofrerem com perturbações externas:

4. "É um ambiente tranquilo e silencioso." (Aluno D, $3^{\circ}$ ano E.M)

No entanto, esse dado revela que outros $48 \%$ não dispõem de um ambiente adequado para a concentração em seus estudos, o que, sem dúvidas, reverbera negativamente em seu processo de aprendizagem. E mesmo quando o ambiente é adequado, os próprios estímulos recebidos em frente ao computador são suficientes para distrai-los das aulas:

5. "Eu faço tudo pelo computador, então, às vezes, eu me distraio com uma ou duas coisas." (Aluno $\mathrm{E}, 1^{\circ}$ ano E.M)

Ainda assim, pode-se considerar que a disponibilidade de um computador para estudos é para poucos, já que $55 \%$ dos alunos acessam o conteúdo on-line exclusivamente pelo celular, o qual muita vezes é emprestado por alguém próximo.

Desta forma, no que tange à posse dos dispositivos tecnológicos, dos $45 \%$ que disseram ter acesso a aulas por computador, $7 \%$ precisaram pegar emprestado algum dispositivo eletrônico para acessar as aulas.

A maior parte dos alunos, 69\%, conseguiu continuar seus estudos de forma exclusivamente remota, mediada por recursos tecnológicos. Os outros $31 \%$ que não conseguiram, precisaram buscar material impresso na escola para complementar as aulas com o auxílio da apostila.

No que diz respeito aos materiais disponibilizados para a realização dos estudos de forma remota, $43 \%$ não estão plenamente satisfeitos com o material, por sentirem a necessidade de interação socioemocional:

6. "Estou parcialmente satisfeito por conta da baixa interação com os alunos mediante a esta situação." (Aluno F, $1^{\circ}$ ano E.M)

Essa baixa interação presencial, por conta do isolamento social, também reverbera negativamente no processo de aprendizagem dos alunos, pois professor e aluno têm a necessidade de trabalharem dentro de uma dinâmica construtiva de diálogo e parceria, garantindo que o processo de ensino e aprendizagem se torne possível e prazeroso (FRANCISCO; ARAÚJO, 2014).

O comprometimento dos professores com a qualidade do ensino apesar das adversidades tem sido um fator importante para a manutenção dos engajamento das turmas, o que resulta em $57 \%$ dos alunos satisfeitos com a qualidade do material oferecido:

7. "A professora explica muito bem mesmo nas aulas online, o conteúdo é interessante."

(Aluno $\mathrm{G}, 3^{\circ}$ ano E.M)

Mesmo assim, por si só, esses esforços não têm sido suficientes para estimular o estudo dos conceitos da disciplina fora do horário das aulas, já que 53\% afirmaram dedicar menos de uma hora semanal para os estudos de Ciências ou Biologia, elencando entre os principais motivos a distração com outras atividades. 
No que diz respeito à experiência pessoal dos alunos com o novo contexto escolar motivado pela pandemia, destacam-se os seguintes comentários:

8. "Muitas vezes é complicado e difícil, mas é necessário se adaptar a esta nova realidade." (Aluno $\mathrm{H}, 1^{\circ}$ ano E.M)

9. "Não tem muito o que fazer para algo que não estávamos preparados. Até ter vacina, é melhor continuar as aulas assim." (Aluno I, $3^{\circ}$ ano E.M)

10. "Minha professora explica absolutamente tudo, ela é muito atenciosa, isso faz com que as aulas se tornem muito melhor." (Aluna $\mathrm{J}, 3^{\circ}$ ano E.M)

11. "Fico muito feliz em ter um professor que transmite boas energias, porque é entediante assistir uma aula que ninguém está animado. Então o professor demonstrar que está feliz logo cedo nos motiva, e responder o aluno sempre que possível também é muito legal, às vezes tenho dúvidas em Biologia e sei que tenho a quem recorrer. Porém, em muitas matérias isso não acontece. Por isso, estar disposto a ajudar é essencial.” (Aluna K, $2^{\circ}$ ano E.M)

De acordo com as respostas coletadas, esses últimos exemplos representam os temas mais impactantes para os alunos: a adaptação ao ensino remoto, a esperança na volta do ensino presencial, e a dedicação e atenção dos professores.

\section{CONCLUSÃO}

No geral, podemos concluir que a falta de interação pessoal entre professores e alunos gerou uma dificuldade maior durante a aprendizagem, porém, o bom profissionalismo dos professores, entusiasmados, empáticos e proativos foi um importante fator que ajudou muito os alunos a superarem as dificuldades. A qualidade do material fornecido, bem como a grande quantidade de meios de aprendizagem oferecidos pelo poder público foram de extrema importância e de muita utilidade. Os defeitos ou falta de conexão com a internet foram perturbadores e os alunos puderam recorrer ao auxílio das apostilas retiradas nas escolas. A dificuldade de compreensão do conteúdo da sala de aula aconteceu de forma pontual com os alunos com maior necessidade de aproximação pessoal com o professor, ou por não se adaptarem às aulas com slides. O ambiente desfavorável foi um fator comum entre os estudantes participantes, e um dos principais motivos para que os eles prefiram as aulas presenciais.

\section{DECLARAÇÃO DE INTERESSES}

Nós, autores deste artigo, declaramos que não possuímos conflitos de interesses de ordem financeira, comercial, político, acadêmico e pessoal. 


\section{REFERÊNCIAS}

DE LA TAIlle, Y.; OliveIRA, M. K.; DANTAS, H. Piaget, Vigotski, Wallon: Teorias psicogenéticas em discussão. 28. ed. São Paulo: Summus Editorial, 1992.

FRANCISCO, D. F.; ARAÚJO, R. L. S. A Importância Da Relação Professor-Aluno. Minas Gerais: Unipac, 2014.

GOLDENBERG, M. A arte de pesquisar: como fazer pesquisa qualitativa em Ciências Sociais. 8. ed. Rio de Janeiro: Record, 2004.

LIMA, C.; QUEIROZ, E. C. S. B., SANT’ANNA, G. J. ARelação Entre Concentração EAprendizagem: O Uso De Tidc Para AAprendizagem Do Aprender. In: CIET: EnPED 2018 - Educação E Tecnologias: Aprendizagem e Construção do Conhecimento. Anais. São Carlos: UFSCAR, 2018.

MORAN, J. Metodologias Ativas E Modelos Híbridos Na Educação. In: YAEGASHI, S. et al. (Orgs). Novas Tecnologias Digitais: Reflexões sobre mediação, aprendizagem e desenvolvimento. Curitiba: CRV, 2017, p.23-35.

ROGERS, C. Liberdade Para Aprender. 2. ed. Belo Horizonte: Interlivros, 1973.

Vygotsky, L. A Formação Social Da Mente. 3. ed. São Paulo: Martins Fontes, 1989.

WEISSMANN, H. (org.). Didática das Ciências Naturais: Contribuições e Reflexões. Porto Alegre: ArtMed, 1998.

YUGE, C. Reclamações Sobre Banda Larga Têm Alta De 40\% Durante A Pandemia, Diz Anatel, Canaltech. 2020. Disponível em: <https://canaltech.com.br/internet/reclamacoes-sobre-banda-largatem-alta-de-40-durante-a-pandemia-diz-anatel-169374/>. Acesso em: 15 set. 2020. 


\section{ÍNDICE REMISSIVO}

\section{Símbolos}

$1^{\mathrm{a}}$ e $2^{\mathrm{a}}$ Lei de Mendel 114,116

A

alelos 98, 99, 100, 101, 102, 105, 107, 108, 110, 117, 118, 119, 121, 122, 123, 124

alfabetização científica 42, 44, 51, 61, 62

alginato $42,44,45,46,48,52,53,55,56,57,59,64$

alginato de sódio 42, 44, 45, 46, 53, 56, 57

ambiente escolar $13,29,53,55,58,89$

animais nativos $76,80,84$

animais vertebrados $76,77,78,83$

animais vertebrados e o ser humano 76

Aprendizagem 18, 65, 67, 112

aprendizagem de biologia 114

atividade experimental $44,45,46,53,55,56,58,62$

atividades remotas 11,15

aulas de biologia 28

aulas presenciais $11,15,17,89,90$

aulas remotas 11,13

a vida em sociedade 127

B

Biologia $6,11,14,15,16,17,20,22,24,26,27,37,40,41,63,85,86,88,100,110,112,115,116,124,125,133$

biologia celular 114,115

botânica 65,70

C

campo da ecologia 65,69

campo da nanotecnologia 53,62

caráter histórico e dinâmico da ciência $\square 28,36,37$

carreadores de fármacos $42,43,44$

cátions bivalentes 53,55

ciclo da doença $20,22,23$

ciência como atividade coletiva $\square 28,36,37,38$

Ciências $11,12,14,15,16,18,22,24,26,40,41,43,44,48,50,62,65,67,75,87,91,110,111,112,117,125,137$ 
citologia $37,65,70$

compreensão e fixação das informações 19

comunidade $20,22,25,76,77,78$

conceito de homofobia 127,134

concentração nos estudos 11, 15

conexão de internet 11

conhecimentos da genética 114

consciência biológica 76, 84

construção de cordéis 65,67

conteúdo didático 11,12

conteúdo informativo 20

cromossomos $98,99,100,101,102,104,105,106,108,109,110,114,115,117,118,119,120,121,122,123,124$

$\mathbf{D}$

Dança dos Cromossomos 114, 116

déficit informativo 19

didáticas alternativas 98

dificuldade de entender os conceitos 11

dificuldade na compreensão 97

Dificuldades de aprendizagem 11, 111, 125

dificuldades do aprendizado 11

dinâmica das aulas 87,88

disciplina de genética 97, 115

dispositivo eletrônico 11, 16

disseminação de conhecimento 20, 21

diversidade $71,77,127,132$

doenças negligenciadas 19

dominância completa 98, 100

E

Educação básica 11

educação sexual 127,135

Enfrentamento das visões ingênuas sobre a ciência 28

ensino da hereditariedade 97

ensino de ciências $27,28,32,40,42,51,96,125$ 
ensino de parasitologia 19,22

ensino remoto $11,13,14,17,87,88,89,90,91,92,96$

entendimento sobre a amebíase 20

esferas de alginato $42,45,46,47,48,53,56,57,58,59,60$

espécie humana 77, 101

espermatozoides 98, 100, 102, 107, 108, 109

Estratégias 26, 63, 65

estudantes de biologia 98

Estudos Culturais em Educação 127, 128

estudos histórico-filosóficos 28

etapa experimental 53

F

falta de reflexão sobre a $\mathrm{NdC} 28$

família 76, 80, 136

farmacocinética 42,50

fármacos $42,50,55$

fechamento das escolas 11,12

fenômeno biológico 101, 108, 113, 115

fenômenos biológicos 114

fenótipo 98, 100, 103, 108, 124

ferramenta didática $65,67,114$

ferramenta didática adjuvante 65

fisiologia humana 87, 91, 94

formação dos gametas 114, 117, 118, 119, 121, 124

formato de aprendizagem 11

formulação convencional 42

fusos meióticos 114, 120, 122

G

genótipo 98, 100, 101, 102, 124

graduação nas áreas biológicas 98

H

hereditariedade $98,99,101,110,111,112,113,114,115,125,133$

homem e natureza $76,77,82,84$ 
homem e natureza/vertebrados 76

homem primitivo 76,77

homossexualidade 127, 128, 129, 130, 131, 132, 133, 134, 135, 136, 137

I

Inclusão 11

inteligência cinestésico-corporal 114, 116

interdisciplinaridade 42,50

interesse em aprender 87, 95

J

jovens em idade escolar 11

$\mathbf{L}$

Leis de Mendel 110, 113, 114, 115, 125

Ligação Gênica 114, 116, 121, 123, 125

linguagem e conceitos complexos 19,21

lipossomas 42,44

Literatura $65,74,75$

literatura de cordel $65,66,67,68,73,74,75$

livro paradidático de sexualidade 127, 128, 129, 131, 132

livros didáticos $28,31,32,33,34,35,36,38,39,41,48$

livros didáticos de biologia $28,31,32,34,35,36,38,41$

livros didáticos de ciências/biologia 28

M

manifestações culturais 65,66

materiais didáticos 14, 20, 22, 25, 31, 52, 62, 63

materiais poliméricos 53

mecanismos biológicos 113

medicamentos $42,43,44,58$

meio ambiente $65,69,77,78$

meiose $71,101,114,116,117,118,119,124,125$

Mentimeter 87, 88, 89, 92

Metodologias 14, 18, 65, 95, 96

metodologias ativas $14,87,89,90,91,94,96$

métodos profiláticos 20 
microestruturas 53,55

minimizar prejuízos 11

Ministério da Educação 11, 88

Ministério da Saúde 11

modelos didáticos 24, 98,100

modo de transmissão 20,22

mudanças no âmbito educacional 87, 88

$\mathbf{N}$

nano- e micropartículas 42

nanosistemas 42

nanotecnologia $43,50,53,54,55,56,57,58,61,62,63,64$

nanotecnologia e suas aplicações 54, 57, 62

natureza da ciência (NdC) 28, 29

novo coronavírus 87,88

O

oficinas de versificação 65

$\mathbf{P}$

Padlet 87, 88, 89, 92, 93

padrões de herança 98, 100, 101, 103, 110, 111

pandemia $11,12,14,17,18,87,88,89,96$

pandemia do COVID-19 11, 14

panfletos informativos 20

participação ativa $14,62,87,91,92,93,94,95$

participação mais efetiva 43, 44, 51, 62

Pecha Kucha 87, 88, 89, 90, 91, 92, 93

perspectiva cidadã 127

perspectiva sociocultural 127

plataformas digitais 11,15

polissacarídeo natural 44, 53, 55

poluição $55,65,69,70,82$

povo nordestino 65

principais dificuldades 11

problematização 28, 129, 134 
processo da fecundação 98,101

processo de ensino-aprendizagem 20, 25, 39, 52, 87, 100, 115, 124

professor de biologia 114,125

protozoário Entamoeba histolytica 20, 21

R

recursos didáticos alternativos 19,100

relação ecossistêmica 76,80

responsabilidade com o ambiente 76,84

$\mathbf{S}$

segurança $11,12,81$

simulações 98, 123

sobrevivência $76,78,79,80,83$

subsistência $76,77,79,80,82,83,84$

sub terapêutica 42

suspensão das aulas presenciais 11

sustentabilidade $65,69,71$

T

Tecnologias Digitais de Informação e Comunicação (TDICs) 87, 89

teoria celular $28,31,32,37,38$

terapêutica 42,49

Trilha da aprendizagem $87,89,90,92$

$\mathrm{U}$

uso de jogos 98

V

vírus SARS-CoV-2 11,12

$\mathbf{Z}$

zoologia 65,70 
